\title{
Like-Minded Cooperators-The Research on the Relationship between the CEO Transformational Leadership and the Innovation Behavior of Designer
}

\author{
Chunhong Liu, Tong Niu \\ West Yan'an Road Campus, Glorious Sun School of Business and Management, Donghua University, Shanghai, China \\ Email: newton1985@sina.com
}

How to cite this paper: Liu, C. H., \& Niu, T. (2020). Like-Minded Cooperators-The Research on the Relationship between the CEO Transformational Leadership and the Innovation Behavior of Designer. Journal of Service Science and Management, 13, 567-593.

https://doi.org/10.4236/jssm.2020.133037

Received: April 11, 2020

Accepted: June 25, 2020

Published: June 28, 2020

Copyright $\odot 2020$ by author(s) and Scientific Research Publishing Inc. This work is licensed under the Creative Commons Attribution International License (CC BY 4.0). http://creativecommons.org/licenses/by/4.0/

\begin{abstract}
Based on the human-environment interaction theory, this study intends to expand the existing ASA model by combining the leadership behavior theory and organizational identity theory, and focuses on the role of the model in linking the innovation performance of the $\mathrm{CEO}$ and the $\mathrm{R} \& \mathrm{D}$ staff. Through the above research, the connection path between CEO transformational leadership at the organizational level and employee performance at the individual level has been opened up, and the relationship model between transformational leadership and employee creative behavior has been constructed. Besides, the variable relationship in the model has been verified by collecting questionnaires from fashion designers of 640 clothing enterprises. Data results show that the CEO of transformational leadership on employee leadership fit has a significant positive influence, staff leadership fit have a significant positive influence on identification of leadership, and leadership identity for employees' innovation performance has a significant role in promoting, organizational political climate between CEO of transformational leadership and employee leadership fit to play an important inhibitory effect, namely the high organizational political climate, CEO of transformational leadership has been weakened by the influence to fit the leadership of the staff will be. This research will be an effective supplement to the recent research on innovation behavior and innovation performance at the enterprise and individual levels.
\end{abstract}

\section{Keywords}

CEO Transformational Leadership, Organizational Here Climate, Person-Supervisor Fit, The Personal Identification, The Employee Innovation 


\section{Introduction}

According to the relevant data of China garment association, there are more than 50,000 garment enterprises in China, and the whole garment industry has formed a relatively complete industrial chain. More and more enterprises have started to establish their own brands and carry out independent research and development activities. Meanwhile, consumers at home and abroad have improved their awareness of China's garment industry's independent brands. Study on modern innovative enterprise, the enterprise vitality and competitive advantage comes from the innovative employees within the enterprise innovation performance, this is mainly because that does not have a long term competitive outsourcing innovation technology, this is because any technology that marketization is easy for other enterprises, so it is unable to make enterprise in competition with rival companies in an absolute dominant position, for the enterprise, the competitive advantage of innovative enterprise own $\mathrm{R} \& \mathrm{D}$ activities to form is needed (Feng, 2019). Since the clothing brand market competition at home and abroad, the domestic garment enterprises have realized the original design of product competitiveness, the importance of enterprise vitality, they need most is the product innovation, from design to production in product research and development of the designer, designer's creativity has become an important source of enterprise's competitiveness (Hao, 2019).

For China's small and medium-sized enterprises, which are dominated by innovation, their CEOs attach much more importance to the innovation and growth of enterprises than others (Link \& Bozeman, 1991). Due to the fierce competition in the industry in which these enterprises are located, the CEO of these enterprises must always be able to perceive the changes in the external and competitive environment of the enterprise, grasp the current and future development direction of the enterprise, and then influence other senior executives and employees of the enterprise through his transformational leadership behavior (Lee \& Dai, 2019). CEO in promoting enterprise innovation plays an important role, the reality of Chinese enterprises' external economic environment and the enterprise internal management environment for the relationship between the leadership and staff has provided the new situational change requirements, but previous studies on transformational leadership incentives and support, ignoring the transformational leadership behavior by express enterprise strategic target of claims arising from employee innovative behavior, motivation and support more is reflected in the pay of one-way, more real leadership behavior and corporate practice should also include the leadership demands of employees, therefore, The focus of this study is to focus on how the CEO of the enterprise stimulates the internal innovation motivation of the $\mathrm{R} \& \mathrm{D}$ personnel through the interaction of "the way is in coordination", and then to show it through individual innovation performance (Peterson, Walumbwa, \& Byron et al., 2009; Ling, Simsek, \& Lubatkin et al., 2008; Jung, Wu, \& Chow, 2008).

First of all, as for the innovation behavior of enterprise R \& D personnel, re- 
levant research shows that enterprises will improve the innovation performance of employees through a series of management behaviors. The enterprise management behavior of the individual innovation performance impact can be illustrated by the quality of the enterprise and individual interaction, such as leadership subordinates interaction and leadership or organizational support, psychological authorization, employee trust, the psychological contract of employees and enterprises, etc., these studies are mainly based on the social exchange theory for employees self-perception they return to the enterprise's obligation or liability, which is just one aspect of the enterprise management practice (Rajagopalan \& Datta, 1996; Sattayaraksa \& Boon-Itt, 2016; Saeed, Afsar, \& Cheema et al., 2018; Young, 2012; Dhar, 2016; Luoh, Tsaur, \& Tang, 2014; Pieterse, Van Knippenberg, \& Schippers et al., 2010). Real enterprise management or leadership in the practice of enterprises in addition to support for the staff, will be based on the needs of their own to be support staff requirements, For example, Cai et al. (2013) pointed out in their research, that transformational leadership including consistency and individual differentiation leadership team two kinds of behavior, the former including vision, encourage cooperation, demonstration and high performance requirements, while the latter includes individual support and talents incentive, and the high performance requirements in the relevant study is not effective to reflect, employees agree with the concept of leadership can well reflect the interaction between the leadership and staff quality. It can effectively predict the impact and behavioral response of employees (Hu et al., 2014; Huang, 2012).

Are introduced in recent years, the existing related research staff organization fit as a corporate or mediation between leadership behavior and employees work results of variable mechanism and the mediation mechanism is explained by ASA frame model, but pay more attention to research is based on the model of ASA enterprise environment for employees (current and potential), the influence of their research is more of the related factors of ASA precipitation, in order to confirm the ASA model, however, should see, ASA framework still exists the problem of insufficient understanding of process, this is because the interaction between enterprise and individual is a two-way process for a long time, However, it cannot be said that as long as the enterprise gives certain support to the employees, the employees will show a strong innovation reward behavior. This is because if the employees do not recognize the enterprise and the core leadership, and effectively bind the development of the enterprise with their own personal interests, the innovation behavior of the employees will hardly be more frequent and prominent (Cai, Jia, \& You, 2013; Adkins \& Russell, 1997; Zhao, 2013; Zhao \& Long, 2004; Zhao \& Long, 2008; Zhao \& Long, 2009; Zhao \& Long, 2010; Verquer et al., 2003; Liu \& Chen, 2011; Tan, 2012; Tang, Lu, \& Lee, 2010; Chatman, 1989; Boehm, Dwertmann, \& Bruch et al., 2015). Related research shows that leadership in shaping the corporate culture and business environment plays an indispensable role, thus it can be seen in the ASA model, in addition to the ASA model in the process of affect employee support each other and 
get to the staff to enterprise's identity, transformational leadership behavior exists in the ASA model prepositional effect (Braun, Peus, \& Weisweiler et al., 2013; Gong, Huang, \& Farh, 2009; Abedi Jafari \& Aghaz, 2008).

Second, In the process of the CEO's interaction with employees through the behavior of change, there is a very important interference factor is the enterprise management practice, The system, culture and management practice in an organization have an important influence on the perceived fit between people and the organization, such as "material incentives", "competition" can promote the fit of the senior management team and organizational goals, the characteristics of organizational culture will affect individual and organizational fit (Gumusluoglu \& Ilsev, 2009; Zhao \& Long, 2010; Tan, 2012). In the theory of personal-environment matching, one of the important factors influencing the fit is the organizational political atmosphere, which is the perspective of various unreasonable phenomena in the enterprise from the perspective of employees ( $\mathrm{Gu}$ musluoglu \& Ilsev, 2009; Bass, 1999). When companies such as clings to the enterprise have been found in the powerful people, meet the status quo, the behavior phenomenon such as flattery, lead the change of motive and goal of information will be wrong understanding, the core staff of inhibiting bonding interaction between the leadership of the staff and the forward process, before the established sense of fit between employees and leadership will be damage and erosion.

In conclusion, this study proposed combining the theory of leadership behavior, organizational identity theory to expand existing ASA model, pay attention to the model in the links between CEO and enterprise R \& D innovation performance, which will be conducive to get through organizational level, the CEO of transformational leadership to the connection between the individual level of employee performance path, it will be for the recent about enterprise and individual level separately complement of innovation behavior and performance research. At the same time, the Organizational here climate is introduced into the relationship between leaders and individual leaders, so as to better clarify the functional intensity and boundary of ASA model (see Figure 1).

\section{Theory and Hypothesis}

In the basic model of this study, ASA framework occupies a core position, and

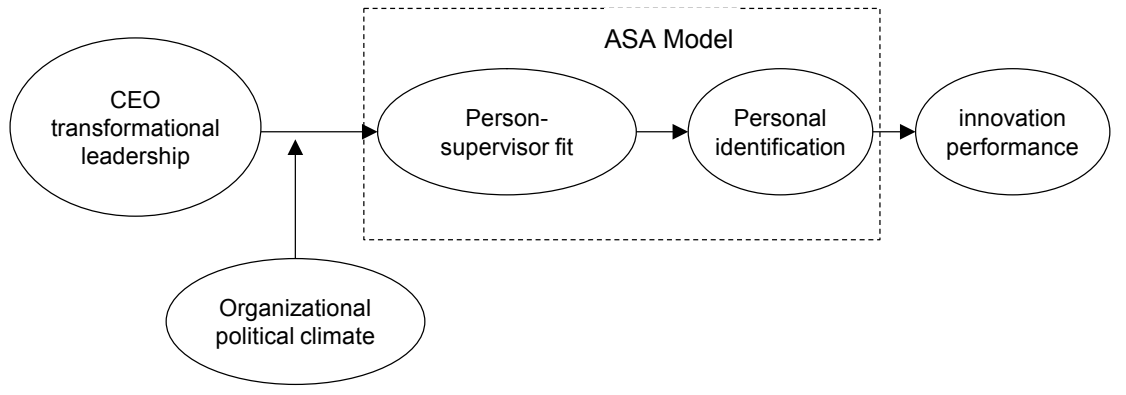

Figure 1. The research model. 
the existence of an enterprise as an entity is visualized through the dynamic process of mutual selection between enterprises and employees. Then the transformational leader is introduced into this dynamic process as a precondition and the effect of organizational political atmosphere on the influence of transformational leader in enterprises is discussed. Finally, the innovation behavior of employees is standardized into innovation performance, so as to facilitate the quantification of the model.

\subsection{CEO Transformational Leadership Is Consistent with Employee-Leader}

For employees in an enterprise organization, an important task of a leader is to create an atmosphere in the enterprise to promote positive emotions, attitudes and emotions among employees. Every move of the leader plays a role of signal transmission, which will promote the formation of common values and attitudes among employees ( $\mathrm{Yu}, \mathrm{Liang}, \& \mathrm{Fu}, 2019)$. As the agent of the organization, leaders, especially senior leaders, not only control the resources of the organization and the distribution of power within the organization, but also are the key factors for the real implementation of the organizational culture. Even if employees think it fits into the overall organizational culture, they still rely on how their leaders transfer organizational culture and values into their daily work environment. Organizational culture often represents a more distant work environment, while the behavior of leaders represents a closer working environment for employees. If employees believe that their values, traits, interests and hobbies are highly compatible with the values, traits, interests and hobbies of leaders, it will promote a more positive view of the organization to a greater extent, and it will be very beneficial to weaken employees' negative view of the organization (Kacmar \& Ferris, 1991).

People-environment fit theory suggests that the fit between employees and professional environment will bring positive work attitude and behavior, the theory is that only when the employee individual and working environment to achieve highly fit, to achieve the fit of people and environment, the interaction between staff and work environments are the important factors that affect employee behavior, when work environment to meet the demand of employees, which meet people-environment fit, can produce positive results (Gumusluoglu \& Ilsev, 2009); on the other hand, if the work environment is not satisfied, it will cause the employees to have tension, negative emotions and conflict experience (Gumusluoglu \& Ilsev, 2009). Employee-leader fit is a core concept in the theory of human-environment fit. Employee-leader fit refers to the fit between employees and leaders, and refers to the similarity between employees and leaders in terms of values, personality, work style and lifestyle (Tsui, Zhang, \& Wang et al., 2006). According to Wexley et al. (1980), if employees believe that their values, traits, interests and hobbies are consistent with those of leaders, they will be satisfied with their work and work environment. It can be seen that the employee-leader fit will have a positive effect on the work performance of em- 
ployees (Becker, Cropanzano, \& Sanfey, 2011).

Transformational leadership is to motivate employees by changing their values and beliefs, improving their needs, or planning a vision and mission for the organization, so as to make employees realize the value of work goals, and then make employees willing to make more efforts in exchange for positive work results. Or to help employees learn new skills and develop new potential, thereby enhancing the overall effectiveness of the organization (Avolio \& Bass, 1995). Relevant research shows that transformational leadership can promote employee creativity and organizational innovation (Van Vianen, Dalhoeven, \& De Pater, 2011). According to the theory of ASA, leadership and staff because of the values and qualities, interests, hobbies and so on similar and attract each other, similar to attract hypothesis points out that employees feel is similar with other individuals, when employees fully understand the leader's values, characteristics, interests, hobbies, he will do best for employees-leadership behavior, and this behavior, tend to be confirmed with their leader values is fit, characteristics, interests, hobbies, or is gradually close to the leader's values, characteristics, interests, hobbies and eventually achieve highly fit, of course, it may also be that he or she finally leaves because he or she cannot fit in with the leader's values, traits, interests and hobbies (Wexley, Alexander, \& Greenawalt et al., 1980). However, in either case, the end result is that the remaining employees tend to fit in with the leader's values, traits, interests and hobbies, so the employee-leader fit is high to a large extent. In summary, this study proposes that:

Hypothesis 1: CEO transformational leadership has a positive impact on employee-leader fit.

\subsection{The Regulating Role of Organizational Here Climate}

All the activities of an organization are carried out in a specific environment. For leadership behavior, organizational climate, tasks, structure and position power, environmental uncertainty, organizational size, etc. are important influence factors of the effectiveness of the behavior (Pieterse, Van Knippenberg, \& Schippers et al., 2010), although the CEO transformational leadership may affect employee's leadership, but in a different environment, leadership style to fit the leadership of the staff and the effect may be different (Huang, 2012). The influence of CEO transformational leadership on employees' leadership may also be influenced by leadership substitution or leadership offset.

The so-called leadership offsetting factor refers to the fact that in certain circumstances, the influence of the leader will be hindered or weakened, thus unable to produce the desired effect; The factor of changing the leader refers to that the influence of the leader can be replaced under certain circumstances, and the result is not only that the role of the leader cannot achieve the expected effect, but also becomes unnecessary (Avolio \& Bass, 1995). In other words, in the case of "leadership replacement factor", the demand of clothing designers for the leadership of the $\mathrm{CEO}$ of the enterprise will decline. In this case, "leadership re- 
placement" is adapted to the situation, and through this, the importance of the leadership of the CEO of the enterprise is reduced. Therefore, in a certain sense, the effectiveness of CEO's transformational leadership behavior is bound to be affected by the leadership replacement factor or the leadership offset factor, so that clothing designers show different demands for CEO leadership, and the effectiveness shows a huge difference (Byrne, 1971).

Organizational political atmosphere is the common perception of members of the organization for the lack of guidance on organizational goals, the unfair and unjust interests held by group members due to self-interest, and the behavior that is not generally recognized by the organization (Kerr, Garvin, \& Heaton et al., 2006). It can be seen that the organizational political atmosphere belongs to a specific organizational atmosphere and is regarded as a negative organizational atmosphere by scholars. Scholars often believe that the organizational political atmosphere is more likely to have a negative impact on the inside and outside of the organization and affect the organization's image. The realization of organizational targe. Since the organizational political atmosphere is not guided by the general consensus of the organizational goals or any fair standards, it often does not take into account any moral checks and balances, so that it is easy to enhance the interests of specific individuals or groups. When high, the organization will form exclusivity and form a specific "social circle" (Xu \& Shi, 2005) which will make the fashion designer question and negative attitude to the CEO leadership, especially when the fashion designer feels deprived and not because of the political atmosphere In fair treatment, the individual values of the clothing designer and the values of the CEO leadership are more likely to diverge, the employee-leadership agreement between the clothing designer and the CEO is easier to reduce, and the clothing designer is more likely to be hostile and resistant to the CEO leadership. Not conducive to the improvement of employeeleadership.

Based on this, the research assumes that:

Hypothesis 2: Organizational here climate regulates the relationship between transformational leadership behavior and employee-leader fit. The influence degree of CEO transformational leadership on employee-leader fit is lower in high organizational atmosphere than in low Organizational here climate.

\subsection{Employee-Leader Fit and the Personal Identification}

Self-concept refers to employees' perception of themselves, such as their own abilities, attitudes, values, likes and dislikes. Among them, the sense of identity is of great significance, which affects employees' understanding of self-identity, values and beliefs (Drory, 1993). The employee's sense of identity with the leader can also be called leadership identity, which refers to "the degree of overlap between the subordinates' perceived self and leadership identity, which is a kind of personal identity on a dual relationship level" (Dexter, 1976). According to social identity theory, when employees form self-concepts, they mainly realize 
their self-concepts through the relationship with the organization itself or other important people (such as leaders) (Van Knippenberg, Van Knippenberg, \& De Cremer et al., 2004). Leadership identification is a state in which employees define themselves according to their relationship with leaders. When employees' understanding of leaders is integrated into self-concepts, leadership identification is formed (Lee, Zhang, \& Long, 2015). In fact, the formation of leadership identification is often a complex psychological process. In this process, it involves not only employee evaluation of employee-leadership relationship, but also employee perception and evaluation of leadership charm, emotion, and motivation to follow (Drory, 1993). Leadership identification refers to the degree to which employees perceive that they overlap with their leadership identities (Dexter, 1976). When employees find that they have similar interests, personalities, and personality traits with leaders, they are likely to be attracted by the attitudes and behaviors of leaders (Tajfel \& Turner, 1985), and actively interact with leaders. Through continuous interaction and communication, there is a high degree of personal attachment, and this sense of attachment is an important connotation of leadership identification (Dexter, 1976). On the other hand, employees will classify leaders according to their similarity to leadership characteristics (Sluss, Ployhart, \& Cobb et al., 2012). Leaders, as one of the key and important members of the organization, control the distribution of resources and power within the organization. Employees will actively compare leaders as a reference and define their identity. When the personality and personality characteristics of the employee and the leader are similar, the employee will divide the leader into "internal groups" and continue to strengthen the preference and recognition of the leaders.

The perception of the similarity between the individual employee and the leader affects the employee's positioning of the employee and leadership relationship and the depth of the corresponding relationship with each other, which in turn affects the employee's specific behavior and behavioral consequences. The CEO's transformational leadership's intellectual stimulation and personalized care of the fashion designer can help different fashion designs to enhance their sense of fit with the leader. When the fit of the fashion designer and the CEO's leadership is high, because the fashion designer and the CEO's leadership have more Similarities, it is easier for fashion designers to have a positive view of CEO leadership, which promotes the individual values and leadership values of fashion designers to be consistent. This result will also be mapped to employees' self-concept and self-definition. Based on this, this study proposes:

Hypothesis 3: employee-leader fit has a positive effect on leader identity.

\subsection{Leaders' Recognition and Employees' Creativity}

Identity is an important part of self-concept, which refers to "the extent to which an individual sees himself or herself as an individual, a partner, or a member of a group" (Byrne, Clore, \& Smeaton, 1986). Although the formation of leadership 
identity is often a complex psychological process, once the formation of leadership identity, it is likely to have a significant impact on employees' work motivation, work behavior and work results (Tajfel \& Turner, 2001). The higher the sense of leadership, the more willing the employees are to strengthen the good relationship between them and the leaders, the more willing they are to internalize the organizational vision, and the more willing they are to work for the organizational goals of the organizational performance.

Compared with individual identity and organizational identity, leader identity is one of the most important mechanisms affecting employee behavior (Fang, 2008). When employees have a high identification with the leader, they will take the leader's values and beliefs as the reference point and take the individual employee as part of their self-concept (Sluss \& Ashforth, 2007). Employees with a high degree of leadership approval tend to have more positive work attitudes and behaviors (Fang, 2008). At the same time, in an organization, employees' perception of the similarity between themselves and leaders in such aspects as interests, hobbies, characteristics and values can enhance their sense of security and belonging, enhance their sense of mission and responsibility to take innovative actions, stimulate their innovative behaviors, and thus enhance their creativity (Yan \& Chen 2013).

Relevant studies show that the recognition of CEO leaders will strengthen their psychological and emotional connection with leaders and make them more willing to share the joys and sorrows with leaders. Therefore, fashion designers find the inner power of creativity, and they will actively engage in work and give full play to their initiative (Kark, Shamir, \& Chen, 2003). On the contrary, clothing designers who do not agree with the leadership of the CEO will be psychologically and emotionally alienated from the leadership. They are not willing to try their best to help the leadership to achieve the ultimate goal of individual creativity, and will show more negative work performance (Kark, Shamir, \& Chen, 2003). Therefore, the recognition of leaders is closely related to the individual creativity of clothing designers. Clothing designers with high recognition of leaders are more willing to take the future development of the organization as their own responsibility, naturally reach a consensus with the vision of the organization, and achieve the expected work goals or even produce more work results through individual creativity of employees. Therefore, employees' sense of leadership can affect their individual creative behaviors. In summary, this study proposes the following hypothesis:

Hypothesis 4: leader's recognition has a positive impact on employee creativity.

\subsection{The Mediating Role of Employee-Leader Fit and the Personal Identification}

According to the leadership style theory, the encouragement of the CEO's transformational leadership and the support of the organization will encourage the 
fashion designers to exert their creative behaviors and show more creative results in their work. Basu and Green (1997) found that transformational leadership and staff are negatively related ideas, Jaussi and Dionne (2003) found that transformational leadership no significant effect on employee creativity, this study thought it should be there is some mechanism process between leadership and staff have not been excavated, and this mechanism is a key link between leadership and employee innovative behavior, this link determines the relationship between transformational leadership behavior and employees' innovative behavior emphasis and direction.

Based on the expanded "ASA framework" of this study, it can be seen from two aspects that transformational leadership is likely to affect the employee innovation through the Person-the supervisor fit and the personal identification. On the one hand, CEO of transformational leadership by focusing on fashion designer's personal development needs, influence its normative belief and behavior attitude, thus inspire fashion designers innovation consciousness, at the same time, the important features of transformational leadership is good at creating a creative atmosphere of the organizational environment (Basu \& Green, 1997), CEO of transformational leadership behavior will bring enterprise innovation atmosphere of the organizational environment, thus to improve clothing designer staff individual creativity; On the other hand, transformational leaders are good at setting long-term goals for employees and motivating them to use new methods and methods to achieve this goal (Jaussi \& Dionne, 2003).

As mentioned above, CEO's transformative leadership behavior may have a positive effect on employee-leadership fit, and employee-leadership fit will have a positive effect on leadership identity, which will also have a positive effect on individual employee creative behavior influence. Therefore, in the mechanism of transformational leadership behavior on employee individual creativity, employee-leadership fit and leadership identification may play an intermediary role. On the one hand, the idealized influence and inspirational incentives in the CEO's transformative leadership behavior can strengthen the apparel designer's sense of identification with the leadership's values, characteristics, interests, and hobbies, and gradually feel the consistency with the leadership's internal values, thus forming High employee-leadership fit. On the other hand, the high degree of employee-organization fit, the similarity of the individual characteristics of the fashion designer and the CEO leadership enhances each other's influence (Wexley, Alexander, \& Greenawalt et al., 1980), and it is easier for the fashion designer to have a strong sense of identity with the CEO leadership, as belonging to the CEO The organization represented by the leader is proud and gradually develops a high level of leadership identification. Finally, fashion designers with a high sense of leadership will closely connect the success of the CEO's leadership work with themselves, strive to achieve leadership and organizational goals, and then show more creative behavior. Therefore, this study proposes the following assumptions. 
Hypothesis 5: employee-leader fit and leader identity play an intermediary role between CEO transformational leadership and employee creativity.

\section{Research Design}

\subsection{Research Samples}

The research work of this study conducted four questionnaire surveys on 1200 apparel processing and design company apparel designers on a well-known apparel designer exchange platform from June 31 to August 18, 2019. After obtaining the consent of these 1200 individuals, data were collected through online survey. The specific operation process is as follows: first, the prepared questionnaire will be recorded on the questionnaire star network research platform; Then, through WeChat, the completed questionnaire network link will be directed to all the previously agreed respondents, who will fill in and submit the questionnaire on the computer or mobile phone. In order to reduce Common Method Variance (CMV), this study adopted the Method of collecting data at multiple time points, and the interval of each two surveys was set at two weeks. In order to ensure the institute with the quality of the data, in the process of research has taken the following measures: First, through the platform focused training beforehand way told beforehand that respondents in this survey will be divided into four times, in order to ensure the four times data can be matched, set the respondents in the link of electronic questionnaires submitted WeChat ID required specification requirements, at the same time, also asked respondents each time at the end of the questionnaire to provide his cell phone number after four Numbers and he/she is my commonly used E-mail. Second, the respondents will be told in advance that they will get the corresponding labor fee (60 yuan/person) if they participate in the research. Two-thirds of the total labor fee will be paid on average after the first three surveys, and the remaining labor fee will be paid after they complete the fourth survey and are confirmed as qualified by the researchers. Third, the data extracted by the researchers were collected from the respondents after they submitted the questionnaire, and the reviewed data were downloaded from the background of the questionnaire to protect the privacy of the respondents and encourage them to express their true thoughts when filling in the questionnaire. After the completion of the first questionnaire, a total of 1000 people, including 1200 people, submitted the questionnaire (Because the questionnaire must be filled in before it can be submitted, some designers give up the questionnaire due to the strict requirements for questionnaire filling and submission). The second questionnaire is after the first screening questionnaire (Because the questionnaires are collected through online tracking, the questionnaires must be filled in before they can be submitted. There are no questionnaires that do not fill in all the items in the questionnaire, because some designers will not fill in carefully to complete the task. Questionnaire, we delete those samples that only select one scale score in the questionnaire). A total of 760 questionnaires were collected for the remaining 900 people 
who filled in the valid questionnaires before. After screening the second questionnaire, the third questionnaire was sent to the remaining 736 people who filled invalid questionnaires in the second time, and a total of 680 questionnaires were collected. The fourth questionnaire was also sent to the remaining 675 people with valid questionnaires after screening the third questionnaire, and 670 questionnaires were eventually returned. After matching the phone number and WeChat ID (four times, WeChat must match the last four digits of the phone number), the final valid questionnaire was 640 copies. The control variables include the gender, age and educational background of the individual, and the gender, age and educational background of the CEO.

\subsection{Variable Measurement}

The scales used in this research institute all adopt the mature scales of articles published in well-known domestic and foreign journals. For the English scales of foreign journals, two domestic doctors engaged in human resources management research are required to complete the work. Among them, we have adopted paper-and-pencil translation and re-translation procedures, that is, one of the doctors translated the scale into Chinese. After several master students read the scale in Chinese and English to successfully understand their corresponding meanings, another doctor returned it. Translated into English, the researcher will check the integrity of the original English scale to finalize the essay. The scales in this study were measured using Likert's five-level scale (1 means "very disagree", 2 means "disagree", 3 means "not sure", 4 means "agree", and 5 means "strongly agree"). The following is the specific scale and its reliability.

Transformational leadership: In this study, eight questionnaire scales developed by Waldman, Ramirez, House, and Puranam in 2001 were used and evaluated by employees. Among them, transformative leadership featured "moral conduct", "vision motivation", "leadership charm The conceptual attributes of", such as "CEO will not care about personal gains and losses for the benefit of the company (or collective)", "CEO will show great ability, courage and confidence", "CEO will describe an inspiring future for everyone." The reliability coefficient of this scale in this study is 0.93 , which is very in line with the requirements of data measurement.

Organizational political climate: This study uses a 12-item scale developed by Kacmar and Ferris (1991), which is evaluated by employees. It includes general political behavior and "going to get ahead" political behavior, pay and promotion policies in three aspects, such as "In the organization, I think the powerful groups in the organization are rampant", "In the organization, I feel that partiality makes people in the organization unable to advance", "In Decisions about income distribution and promotion in an organization will be influenced by politics". The overall reliability of the scale in this study is 0.95 .

Person-supervisor fit: In this study, we used the same scale with employee- 
organization fit (changing the organization in its item to leadership), which was developed by Cable and Derue (2002) and has 9 items, among which the related items can effectively reflect the "complementary fit" and "consistent fit" between individuals and transformational leaders. Such as transformational leadership will request and payment reflected in leadership behavior such as "leadership can satisfy my needs", "is a good match between leadership and I", "I think my personality traits and leadership image feature matching", "I think the leadership values and personality is able to reflect my own values and personality" in this study, the scale of citic degree coefficient of 0.94 .

Leadership identification: In this study, using the ten-item scale developed by Kark, Shamir, and Chen (2003), which was evaluated by employees, the main measurement items are "When someone criticizes my CEO for leadership, I feel like "I personally attacked me", "I will praise my CEO leadership as a good working partner in front of friends", "Being a subordinate of my CEO leadership is very important to me", "I think my CEO leadership is successful and A symbol of achievement." The measurement reliability of the scale in this study is 0.96 .

Innovation performance: The individual innovation behavior scale used in this research comes from the nine-item scale developed by Janssen (2001), which mainly includes (Idea Generation), (Idea Dissemination), and (Idea Implementation) three dimensions, each of which has three items. This study focuses on the implementation of individual innovative behaviors. Although creative generation and creative dissemination is also a manifestation of individual innovative behaviors, it is based on Ng and Lucianetti (2016). The three behaviors indicated in their research are sequential. In different scenarios, different innovative behavior scale dimensions can be used to evaluate individual innovation performance. In this study, we use individuals in enterprises of creative implementation behaviors to measure individual innovation performance, because for clothing design companies, quickly putting creativity into behavior can not only effectively evaluate the innovation performance of employees, but also effectively reflect the substantive impact of CEO leadership. Employee's innovation performance specifically includes: "I can transform ideas into satisfactory applications", "I can introduce ideas into work in a systematic way", "I will evaluate the effectiveness/practicability of ideas". In this study, the measurement reliability of the scale was 0.89 .

\section{Data analysis and Results}

\subsection{Confirmatory Factor Analysis}

In order to test the structural validity and relevant reference indexes among the key variables "transformational leadership", "Organizational here climate", "the Person-the supervisor fit", "leadership identification" and "innovation performance", this study used Mplus 7.0 to conduct confirmatory factor analyses (CFA) for the key variables (Janssen, 2001). The results showed that the fivefactor model was in good agreement $\left(\mathrm{X}^{2}(94)=311.18, p<0.01\right)$. RMSEA $=0.06$, 
TLI $=0.97$, CFI $=0.98$ ), and this model is significantly better than the other number of factor models (see Table 1), indicating that the relevant variables in this study have good structural validity.

\subsection{Descriptive Statistical Analysis}

In this study, Pearson's simple correlation coefficient was used to measure the direction and significance of the relationships among "transformational leadership", "organizational political climate", "employee-led fit", "leadership identification" and "innovation performance". The results are shown in Table 2 . It can be seen from Table 2 that transformational leadership has significant correlation with the Person-the supervisor fit $(\mathrm{r}=0.48, p<0.01)$ and the personal identification $(r=0.19, p<0.01)$. Secondly, there is also a significant correlation between employee leader fit and the personal identification $(\mathrm{r}=0.26, p<0.01)$. Finally, there was a significant correlation between the personal identification and innovation performance $(\mathrm{r}=0.12, p<0.01)$. The above results preliminarily confirm the rationality of hypothesis variables in this study, and provide preliminary evidence for hypothesis verification.

\subsection{Verification of Structural Equation Model and Hypothesis}

In this study, Mplus7.0 software was used to construct structural equations between variables to perform overall calculations on sample data. By comparing the significance of changes in $\Delta \chi^{2} /(\Delta \mathrm{df})$ in different structural equation data results $\left(\Delta \chi^{2} /(\Delta \mathrm{df})>3.84, P \leq 0.01\right)$ to compare the goodness of fit between the new model and the original theoretical hypothesis model (Ng \& Lucianetti, 2016), so as to select the optimal model. Among them, considering that the model also contains adjustment variables and interaction terms, in order to avoid the effect

Table 1. Results of confirmatory factor analysis.

\begin{tabular}{|c|c|c|c|c|c|c|}
\hline & $\chi^{2}$ & df & RMSEA & SRMR & TLI & CFI \\
\hline Null model & $10,367.90$ & 120 & - & - & - & - \\
\hline Five-factor model & 311.18 & 94 & 0.06 & 0.04 & 0.97 & 0.98 \\
\hline $\begin{array}{l}\text { Four-factor model (transformational leadership \& Organizational } \\
\text { here climate) }\end{array}$ & 2490.62 & 98 & 0.20 & 0.16 & 0.71 & 0.77 \\
\hline $\begin{array}{l}\text { Four-factor model (transformational leadership \& the Person- } \\
\text { the supervisor fit) }\end{array}$ & 2219.64 & 98 & 0.18 & 0.10 & 0.75 & 0.79 \\
\hline $\begin{array}{l}\text { Four-factor model (political atmosphere \& the Person- } \\
\text { the supervisor fit) }\end{array}$ & 2733.67 & 98 & 0.21 & 0.19 & 0.69 & 0.74 \\
\hline Four-factor model (employee leader fit \& leader identity) & 2441.19 & 98 & 0.19 & 0.13 & 0.72 & 0.77 \\
\hline $\begin{array}{l}\text { Four-factor model (leadership identification \& innovation } \\
\text { performance) }\end{array}$ & 1375.95 & 98 & 0.14 & 0.11 & 0.85 & 0.88 \\
\hline Single factor model & 7494.44 & 104 & 0.33 & 0.24 & 0.17 & 0.28 \\
\hline
\end{tabular}

Note: $\mathrm{N}=640$. 
Table 2. Mean value, variance and correlation coefficient of variables.

\begin{tabular}{|c|c|c|c|c|c|c|c|c|c|c|c|}
\hline & 1 & 2 & 3 & 4 & 5 & 6 & 7 & 8 & 9 & 10 & 11 \\
\hline \multicolumn{12}{|l|}{ 1. Employee age } \\
\hline 2. Employee gender & -0.08 & & & & & & & & & & \\
\hline 3. Staff education level & $0.41^{* *}$ & -0.01 & & & & & & & & & \\
\hline 4. The CEO age & $0.32^{* *}$ & -0.03 & $21^{* *}$ & & & & & & & & \\
\hline 5. The CEO of gender & $-0.21^{\star \star}$ & 07. & $-0.32^{\star *}$ & $-0.32^{\star *}$ & & & & & & & \\
\hline 6. CEO education level & $0.18^{* *}$ & -0.02 & $38^{* *}$ & $0.53^{* *}$ & $-0.35^{\star *}$ & & & & & & \\
\hline 7. Transformational leadership & 0.6 & 00. & $-0.18^{\star *}$ & $0.10^{*}$ & -0.8 & $-0.13^{* *}$ & & & & & \\
\hline 8. Organize the political climate & 0.03 & 0.03 & 0.03 & $-0.11^{\star \star}$ & 0.06 & -0.03 & 0.05 & & & & \\
\hline 9. The Person-the supervisor fit & 0.08 & -0.02 & $-0.22^{\star *}$ & 0.07 & $-0.18^{\star \star}$ & $-0.25^{\star *}$ & $0.48^{\star *}$ & 0.04 & & & \\
\hline 10. Leadership approval & 0.07 & 00. & $-0.20^{\star *}$ & $10^{* *}$ & $-0.18^{\star *}$ & $-0.18^{* *}$ & $0.19^{* *}$ & $0.11^{* *}$ & $0.26^{* *}$ & & \\
\hline 11. Innovation performance & -0.02 & 0.05 & -0.01 & -0.07 & 0.07 & $-0.10^{* *}$ & -0.03 & $0.42^{* *}$ & -0.06 & $0.12^{\star *}$ & \\
\hline 12. The mean & 34.72 & 1.50 & 2.20 & 35.52 & 1.31 & 2.19 & 3.57 & 3.33 & 3.42 & 4.24 & 3.63 \\
\hline 13. The variance & 8.04 & 0.50 & 0.89 & 8.82 & 0.46 & 0.92 & 0.67 & 0.77 & 0.72 & 0.62 & 0.69 \\
\hline
\end{tabular}

Note: $\mathrm{N}=640 ;{ }^{*} P<0.05 ;{ }^{*} P<0.01$; Gender of employee and CEO: $1=$ male; $2=$ female; Age of employees and CEO: $1=30$ years old and below; $2=31-40$ years old; $3=41$ to 50 years old; $4=$ over 50 .

of multicollinearity in actual estimation, in constructing the product term of the independent variable and the adjustment variable in the specific operation, the independent variable and the adjustment variable are first separately A standardized process was carried out (Muthén \& Muthén, 2012). The interaction terms constructed after normalization do not have residuals themselves. Therefore, in this study, the residuals and factor loads of interaction terms were set according to the recommendations of Cortina, Chen, and Dunlap (2001). The data analysis results show that the hypothesis model in this study fits the data well: $\chi^{2}(379)=$ 1849.24, CFI $=0.91, \mathrm{TLI}=0.90, \mathrm{RMSEA}=0.08$. In order to further explore the intermediary role of employee leadership fit and leadership identification, this study uses the difference in chi-square values between nested models to compare and analyze the complete intermediary model (hypothetical theoretical model) with other nested models (partial intermediary model) (Bentler \& Bonett, 1980), in order to find the best and most concise model (Table 3). According to the above criteria $\left(\Delta \chi^{2} / \Delta \mathrm{df}>3.84, p \leq 0.01\right)$, It can be seen that the goodness of fit of the original theoretical model is the best. The final regression results are shown in Figure 2.

For the hypothesis that CEO transformational leadership has a positive effect on employee leadership fit, the data results are significant $(\beta=0.50, p<0.001)$, which supports the hypothesis of this study. Regarding the inhibitory effect of organizational political atmosphere on the relationship between transformational leadership and employee leadership, data analysis shows that the results are significant $(\beta=-0.23, p<0.001)$, which supports the hypothesis that in a high 
Table 3. Comparison of structural equation models.

\begin{tabular}{cccccccc}
\hline Model \& structure & $\mathrm{X}^{2}$ & Df & TLI & CFI & RMSEA & SRMR & $\Delta \chi^{2}(\Delta \mathrm{df})$ \\
\hline Theoretical model & 696.49 & 204 & 0.95 & 0.96 & 0.06 & 0.09 & \\
Partial mediation model 1 & 1847.31 & 378 & 0.90 & 0.91 & 0.08 & 0.09 & $1.93(1)$, compared with the theoretical model \\
Partial mediation model 2 & 1844.00 & 377 & 0.90 & 0.91 & 0.08 & 0.09 & $5.24(2)$, compared with the theoretical model \\
\hline
\end{tabular}

Note: sample number $\mathrm{N}=640$; in the following part of the mediation model, the path between some variables is added to investigate the change of the fitting degree of the whole model after the path is added (part of the mediation model 1: transformational leadership-innovation performance; Partial mediation model 2: transformational leadership-innovation performance, leadership identification.

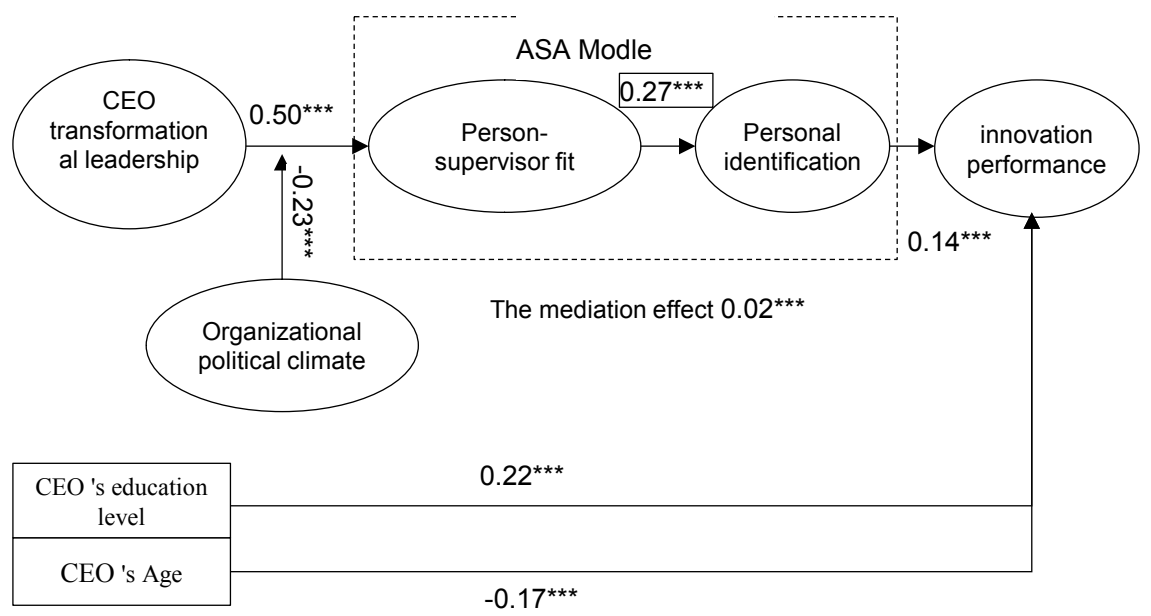

Figure 2. Simplified diagram of normalized path coefficient of the optimal model.

organizational political atmosphere, CEO changes The influence of type leadership on employee leadership fit will be weakened. For the hypothesis that the employee leadership fit mentioned in hypothesis 3 has a positive effect on leadership identification, the data analysis results are significant $(\beta=0.27, p<$ 0.001), which supports this hypothesis. For the hypothesis that the leadership identification proposed by Hypothesis 4 has a positive impact on the individual creativity of employees, the data results $(\beta=0.14, p<0.001)$ also support this hypothesis. At the same time, as an important innovation and contribution of this study is to expand the theoretical framework based on the ASA model, therefore, in the process of program analysis, based on the specific commands of Mplus7.0, this study examines the mediation effect of the expanded ASA framework $(\beta=0.02, p<0.001)$, research hypothesis 5 is also supported by the data.

\subsection{Regulatory Variable Hierarchical Regression Analysis and Hypothesis Verification}

As for the moderating effect of Organizational here climate in the theoretical model on the relationship between transformational leadership and the Person-the supervisor fit, this study used SPSS 22.0 to conduct hierarchical regression analysis of the relationship between them. The results of hierarchical regression are shown in Table 4. Regulating effect of organizational political cli- 
mate can be seen from Figure 3, in the organization of the high political atmosphere environment, transformational leadership positive influence will be influenced by any unhealthy inhibition of tissue culture, because people will think leadership even efforts to meet the requirements of people, also will be strict with employees

Table 4. Test results of hypothesis.

\begin{tabular}{cccc}
\hline & \multicolumn{3}{c}{ Person-supervisor fit } \\
\hline & Model 1 & Model 2 & Model 3 \\
\hline Control variables & & & \\
Workers age & 0.00 & 0.01 & 0.01 \\
Employees' gender & -0.01 & -0.01 & -0.01 \\
Staff education level & $0.13^{* *}$ & 0.6 & 0.03 \\
$\quad$ CEO age & $-0.11^{* *}$ & $-0.13^{* *}$ & $-0.11^{* *}$ \\
The CEO of gender & $-0.09^{*}$ & $-0.10^{* *}$ & -0.08 \\
CEO education level & $0.22^{* * *}$ & $0.20^{* * *}$ & $0.18^{* * *}$ \\
The independent variables & & & \\
Transformational leadership & & & $0.47^{* * *}$ \\
Adjust the variable & & & \\
Organizational political climate \\
Interactive items
\end{tabular}

Note: $\mathrm{n}=640 ;{ }^{* *} p<0.001,{ }^{* *} p<0.01,{ }^{*} p<0.05$.

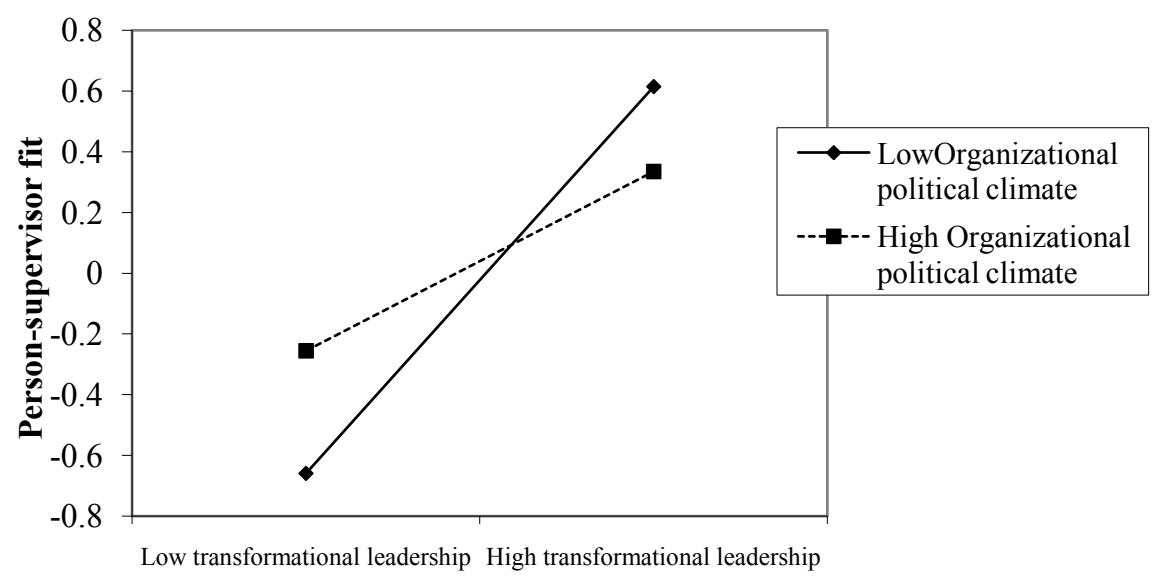

Figure 3. Influence of transformational leadership on the person-the supervisor fit in different organizational here climate levels. 
at the same time, but these will be compromised because of the bad atmosphere in the organization, a lot of people can be got through the path of the rent-seeking by others, at the same time, there are those who can pass the abnormal way to avoid the strict supervision of the leadership.

\section{Research Significance and Prospect}

In this study, through the analysis of 640 companies' clothing designer tracking questionnaire data, The results show that the CEO of transformational leadership on the Person-the supervisor fit has a significant positive influence, staff leadership fit have a significant positive influence on identification of leadership, and leadership identity for employees' innovation performance has a significant role in promoting, organizational political climate between $\mathrm{CEO}$ of transformational leadership and the Person-the supervisor fit play an important inhibitory effect, namely the high organizational political climate, CEO of transformational leadership has been weakened by the influence to fit the leadership of the staff will be. Data results in addition to support the hypothesis that all, the results also show that the CEO's education level has a significant positive effect on innovation performance (beta $=0.22, p<0.001$ ), the age of the CEO has a significant negative effect on innovation performance (beta $=0.17, p<0.001$ ), which to a certain extent, the CEO of the higher education level, it absorbs the market information from the outside world, the stronger the innovation ability of knowledge resources, and can be very good to apply this kind of market information and innovation resources to the enterprise, although there are a lot of risk. However, as the CEO grows older, his propensity to take risks decreases, and these performances will eventually be reflected in the impact on the employee innovation. This study introduces the concept of "transformation" into the existing ASA framework and proposes a new ASA model of "attraction - selection - running-in - transformation", which is verified by empirical research. The conclusion of this study has certain theoretical and practical significance.

\subsection{Theoretical Significance}

First of all, this study confirms that CEO transformational leadership has a significant positive effect on employee leadership fit, which has something in common with the previous positive impact of transformative leadership on employee leadership value convergence (consistent fit) (Cortina, Chen, \& Dunlap, 2001; Bentler \& Bonett, 1980). Of course, in addition to the value convergence, this study also confirmed that transformational leadership has a significant positive impact on the complementary fit of individual and leadership's work requirements and resource support. The influence of leadership values also exists in the resource requirements and resource support of leaders to employees, which can not only effectively summarize the previous research conclusions, but also provide directional guidance for the extensive development of later research. Secondly, this study also confirms that employee leadership engagement 
will have a significant positive impact on employee identification with leadership. This not only clarifies the mechanism and process of how employee leadership engagement plays a role, but also "attracts-The process of selection-running-in is effectively expanded into the framework of "attracting - selecting - running-in - transformation", which will provide stronger theoretical support and direction guidance for future human interaction. At the same time, this study also confirms the intermediary effect of "fit \& identification". The mechanism of employee leadership fit in this study will affect the employee's identification with the leader, which is the "transformation" process in the "attract - select - run-in" framework. This also expands the theoretical basis of other follow-up studies, and further consolidates the process of leadership influencing employees theoretically. In addition to the theory of social exchange, motivation, and identification, there should also be an effective integration of these theories, namely "ASA" + "Transformation" framework, which includes not only social exchange, but also value incentive and recognition. Finally, this study also confirmed that the organizational political atmosphere has a strong inhibitory effect on the CEO's transformational leadership and the significant positive effect on employee leadership fit. This part illustrates the boundary of the influence between personal and leadership fit, namely, CEO leadership and employees. In the process of interacting with employees, consistency fits will be affected by values and personalities, and complementary fits will be affected by resource allocation procedures, interpersonal interaction rules, and specific real-life activities. In addition, these interference factors are based on the "ASA \& Transformation" framework from the analysis, this is helpful for the expansion of the relevant research on "ASA \& transformation" in the later period.

\subsection{Practical Significance}

The conclusions of this study have important reference value for the management practice of leaders in enterprises:

First of all, for leaders in the process of enterprise management practice, they should integrate their own values (such as personality, work standards, corporate culture, etc.), the needs of employees and resource support (such as: job requirements, performance goals, power, funds Support, etc.). Clear and timely delivery to employees, so that employees can form a good fit for employee leadership, how to clearly and timely transmit the above information, CEO leadership can: 1) through the official platform of the enterprise or individual to communicate with employees about certain Interact with each other to allow employees to fully grasp the above information, and at the same time allow employees to effectively supervise the implementation of this information; 2) pass the above information to employees through daily high-level meetings and decision-making execution behaviors. This is a trickle-down effect from the upper layers to the underlying information layer. Although this kind of transmission is slower than the first strategy, this transmission is top-down and more durable 
and stable than the first strategy; 3) Simplify the above information into slogans or slogans through the media of various channels (paper media, multimedia, network, etc.) For employees, although this method will be easier for employees to remember, this simple information transfer can only be supplemented by the two strategies mentioned above, because it cannot be more direct than the first method, and there is no second method. More detailed and clear.

Second, Since employee leadership fit has an important impact on leadership identification, for corporate leaders, in addition to their own values (such as personality, work rules, corporate culture, etc.), the needs of employees and resource support (such as: job requirements, Performance goals, power, financial support, etc.) In addition to clear and timely delivery to employees, the following measures can also be taken to enhance the transformation effect of employees' identification with leaders: 1) Employ employees who are close to their own personalities and can meet their own requirements Incorporate into your own circle, effectively pass your will to them, and brand your own, so as to strengthen their identification with leaders; 2) Focus on rewarding employees who are highly in line with leaders-especially those who listen to leaders, The employees who follow the leader make them different from other employees. Social identity theory points out that when an individual is divided into a certain group, regardless of whether the individual intends to show it or not, they will have a certain sense of identity with the group. These People will be the backbone of enterprise reform.

Finally, Since the organizational political atmosphere will significantly weaken the impact of CEO transformational leadership on employee leadership fit, for companies, they should try their best to reduce the bad atmosphere in the organization from the following aspects: 1) Leaders should try to be clear about the organization in the daily work process The rules and regulations in the company improve the transparency of the strategy implementation process of the enterprise, so that employees have stable expectations of the leader's behavior, so as to avoid the prejudice that "a small number of leaders' credibility gains power in the organization and can dominate the organization". 2) In the process of making decisions, leaders should try to avoid "privacy" behavior. Whether it is to promote subordinates or punish subordinates, they should be open and transparent to prevent employees from forming prejudices for private use of leaders. 3) During the decision-making process, leaders should Attracting enough employees to participate, encouraging employees to dare to speak for the company and defend their own interests, which can enhance employees' support for CEO change leadership and change requirements to a certain extent.

\subsection{Research Advantages, Limitations and Future Prospects}

First, This study puts forward the framework model of "ASA + transformation" on the basis of combing the research literature of personal environment fit, including the influence of leadership at the individual level and organizational lev- 
el into the research model, using the data of clothing processing and trading companies to model The sub-path and total path of the data have been verified by data, which is a summary re-innovation of the previous research framework. Secondly, this research model is proposed by combing the research literature based on the "ASA" framework. This research has formed the most basic. The research framework with "ASA + transformation" as the core, and rigorous theoretical reasoning is also an advantage of this study, because the combing based on theoretical literature can not only make this research model more convincing, but also more easily obtain data support from empirical evidence.

Second, the overall test of this research model has not been paid attention to in previous studies. In this study, the Mplus 7.0 structural equation program was used to effectively test the relevant hypotheses. At the same time, this study adopted a certain matching method (CEO and core employees of the company) when collecting, which removed the complexity of aggregation or verification related data processing required by the cross-layer research, making the test of this research model more It is easier and smoother, because the problem of data or method has opened up the chain of influence from the CEO to the employee level, and on the other hand, it explains the influence from the CEO to the employee. It is more likely to be a spiral-like process. It is through interaction between the individual and the environment that it can function.

Third, Although it can be seen from the calculation of the correlation coefficient in this study that the CEO's transformative leadership is not significantly related to the designer's creative behavior, the CEO's influence on the employee's creative behavior can be transmitted through the "ASA + transformation" intermediary mechanism The relationship between leadership behavior and employee innovation performance shown in previous studies is not clearly confirmed again. At the same time, the two variables that have proved theoretically and methodically unrelated are likely to be linked through an intermediary mechanism, just as scholars Liu, Zhang, and Wang (2012) pointed out that the significance of the intermediary effect is mainly to see whether the intermediary mechanism exists, and whether the variables at both ends of the intermediary are significantly correlated is not a necessary premise (Hoffman, Bynum, \& Piccolo et al., 2011), the results of this study are not only valid explain a mechanism process from transformational leadership to the exertion of employee influence, and also broaden the method path for follow-up research on leadership influence

For this study, due to subjective and objective reasons, there are still the following deficiencies. First of all, in the measurement of the fit variables between employees and organizations and employees and leaders, because there is a perceived fit and a real fit, this study uses a direct measurement method, which is to fill in the questionnaire to match the fit between employees and leaders Measurement, but due to the limitation of the measurement environment, it is inevitable that employees will have a certain deviation when filling in. Although many scholars have shown that the subjective fit measurement can describe the 
true situation of the fit better than the objective fit (Hoffman \& Woehr, 2006), this fit measure uses the subjective measurement method to describe the fit between the person and the environment. The definition of a mental state theory is consistent, but what should not be ignored is that the fit between man and environment is an interaction. A high fit is not only a feeling of the individual, but also should be taken into account by considering the organization's situation (Liu, Zhang, \& Wang, 2012). This is a shortcoming of this study, but there is currently no effective solution to this shortcoming, although there have been studies in China that subdivide PO into value matching, ability matching and demand matching (Cai, Jia, \& You, 2013; Adkins \& Russell, 1997; Zhao \& Long, 2004; Zhao \& Long, 2008), such as However, it is also necessary to make PO research more localized from the following points, such as the objective matching content that needs to be introduced in the PO construction operation, whether these matches should also have an influence weight, and whether these matching content are consistent with other existing There are differences such as personal-job matching, personal-job matching, etc. In the subsequent research, this problem needs to be introduced and considered.

In addition, in the constructive operation of the fit between the individual and the environment, this study will measure the consistent fit and the complementary fit as a whole, but they should not be overlooked because they have different mechanisms and processes, and there is a sequence of influence (Caplan, 1987), although The research has clearly analyzed the difference in attributes and connections between them, but at present they have not been measured separately, and they are also analyzed in the same model. However, in this study, although consistent agreement and complementary agreement were carried out separately explained, but did not realize the separate measurement of the two concepts and the discussion of the relationship between the effects. This is a shortcoming of this study. Of course, this shortcoming has a lot to do with previous research. Many previous studies just matched the relevant values Individual analysis does not pay too much attention to the difference and order of the mechanisms of these two fits. In the subsequent research, this problem can be clarified, so that different measurement scales can be formed to further the research.

Secondly, in terms of data collection, although this study relied on a large clothing designer platform for paid data collection, the data was collected four times, and the relevant designers were busy with work, worried about information leakage, leaving or leaving The questionnaire cannot be completed completely due to other reasons, which makes the final sample of this research model only 640, which is also a shortcoming of this study (Edwards, 1991). More sample data should be collected in subsequent studies to better test the conclusion of this study Robustness enhances the external validity of the conclusion of this study and guarantees the robustness of the conclusion of this study.

Finally, this study mentioned and tested the "ASA \& transformation" model through data, but the "transformation" is a complex cognitive and behavioral process. This research is only through the identification mechanism in the 
process. Subsequent research can also. The above models are tested through intermediary mechanisms such as commitment, psychological safety, psychological empowerment, job satisfaction, etc., to enrich the explanatory power of the theoretical framework.

\section{Conflicts of Interest}

The authors declare no conflicts of interest regarding the publication of this paper.

\section{References}

Abedi Jafari, H., \& Aghaz, A. (2008). Transformational Leadership and Organizational Culture. Knowledge Management Quarterly.

Adkins, C. L., \& Russell, C. J. (1997). Supervisor-Subordinate Work Value Congruence and Subordinate Performance: A Pilot Study. Journal of Business \& Psychology, 12, 205-218. https://doi.org/10.1023/A:1025074219049

Avolio, B. J., \& Bass, B. M. (1995). Individual Consideration Viewed at Multiple Levels of Analysis: A Multi-Level Framework for Examining the Diffusion of Transformational Leadership. The Leadership Quarterly, 6, 199-218.

https://doi.org/10.1016/1048-9843(95)90035-7

Bass, B. M. (1999). Two Decades of Research and Development in Transformational Leadership. European Journal of Work and Organizational Psychology, 8, 9-32. https://doi.org/10.1080/135943299398410

Basu, R., \& Green, S. G. (1997). Leader-Member Exchange and Transformational Leadership: An Empirical Examination of Innovative Behaviors in Leader-Member Dyads. Journal of Applied Social Psychology, 27, 477-499. https://doi.org/10.1111/j.1559-1816.1997.tb00643.x

Becker, W. J., Cropanzano, R., \& Sanfey, A. G. (2011). Organizational Neuroscience: Taking Organizational Theory Inside the Neural Black Box. Journal of Management, 37, 933-961. https://doi.org/10.1177/0149206311398955

Bentler, P. M., \& Bonett, D. G. (1980). Significance Tests and Goodness of Fit in the Analysis of Covariance Structures. Psychological Bulletin, 88, 588-606. https://doi.org/10.1037/0033-2909.88.3.588

Boehm, S. A., Dwertmann, D. J. G., Bruch, H. et al. (2015). The Missing Link? Investigating Organizational Identity Strength and Transformational Leadership Climate as Mechanisms That Connect CEO Charisma with Firm Performance. The Leadership Quarterly, 26, 156-171. https://doi.org/10.1016/j.leaqua.2014.07.012

Braun, S., Peus, C., Weisweiler, S. et al. (2013). Transformational Leadership, Job Satisfaction, and Team Performance: A Multilevel Mediation Model of Trust. The Leadership Quarterly, 24, 270-283. https://doi.org/10.1016/j.leaqua.2012.11.006

Byrne, D. (1971). The Attraction Paradigm. New York: Academic Press.

Byrne, D., Clore, G. L., \& Smeaton, G. (1986). The Attraction Hypothesis: Do Similar Attitudes Affect Anything? Journal of Personality and Social Psychology, 51, 1167-1170. https://doi.org/10.1037/0022-3514.51.6.1167

Cable, D. M., \& Derue, D. S. (2002). The Convergent and Discriminant Validity of Subjective Fit Perceptions. Journal of Applied Psychology, 87, 875-884. https://doi.org/10.1037/0021-9010.87.5.875

Cai, Y. H., Jia, L. D., \& You, S. Y. (2013). The Influence of Differentiated Transforma- 
tional Leadership on Knowledge Sharing and Team Creativity. Journal of Psychology, 45, 585-598. https://doi.org/10.3724/SP.J.1041.2013.00585

Caplan, R. D. (1987). Person-Environment Fit Theory and Organizations: Commensurate Dimensions, Time Perspectives, and Mechanisms. Journal of Vocational Behavior, 31, 248-267. https://doi.org/10.1016/0001-8791(87)90042-X

Chatman, J. A. (1989). Improving Interactional Organizational Research: A Model of Person-Organization Fit. Academy of Management Review, 14, 333-349. https://doi.org/10.5465/amr.1989.4279063

Cortina, J. M., Chen, G., \& Dunlap, W. P. (2001). Testing Interaction Effects in LISREL: Examination and Illustration of Available Procedures. Organizational Research $\mathrm{Me}$ thods, 4, 324-360. https://doi.org/10.1177/109442810144002

Dexter, L. A. (1976). Organizational and Political Climate: A Preliminary Discussion. Political Methodology, 3, 141-158.

Dhar, R. L. (2016). Ethical Leadership and Its Impact on Service Innovative Behavior: The Role of LMX and Job Autonomy. Tourism Management, 57, 139-148. https://doi.org/10.1016/j.tourman.2016.05.011

Drory, A. (1993). Perceived Political Climate and Job Attitudes. Organization Studies, 14, 59-71. https://doi.org/10.1177/017084069301400105

Edwards, J. R. (1991). Person-Job Fit: A Conceptual Integration, Literature Review, and Methodological Critique. In C. L. Cooper, \& I. T. Robertson (Eds.), International Review of Industrial and Organizational Psychology. International Review of Industrial and Organizational Psychology (Vol. 6, 283-357). Hoboken, NJ: John Wiley \& Sons.

Fang, W. (2008). Group Qualification: A New Approach to Social Identity Events. Journal of China Agricultural University (Social Sciences), 25, 89-108.

Feng, L. L. (2019). The Discourse Right of Chinese Costume Design under the Pluralistic Pattern. Jiangxi Social Science, 249-253.

Gong, Y., Huang, J., \& Farh, J. (2009). Employee Learning Orientation, Transformational Leadership, and Employee Creativity: The Mediating Role of Employee Creative SelfEfficacy. Academy of Management Journal, 52, 765-778. https://doi.org/10.5465/amj.2009.43670890

Gumusluoglu, L., \& Ilsev, A. (2009). Transformational Leadership, Creativity, and Organizational Innovation. Journal of Business Research, 62, 461-473. https://doi.org/10.1016/j.jbusres.2007.07.032

Hao, M. (2019). An Analysis of Apparel Design Related Intellectual Property Protection Mode. Intellectual Property, 26-36.

Hoffman, B. J., \& Woehr, D. J. (2006). A Quantitative Review of the Relationship between Person-Organization Fit and Behavioral Outcomes. Journal of Vocational Behavior, 68, 389-399. https://doi.org/10.1016/j.jvb.2005.08.003

Hoffman, B. J., Bynum, B. H., Piccolo, R. F. et al. (2011). Person-Organization Value Congruence: How Transformational Leaders Influence Work Group Effectiveness. Academy of Management Journal, 54, 779-796. https://doi.org/10.5465/amj.2011.64870139

Hu, L., Feng, Z., Liu, C. et al. (2014). The Impact of Relative Leader-Member Exchange on Employees' Work Behaviors as Mediated by Psychological Contract Fulfillment. Social Behavior \& Personality An International Journal, 42, 79-88. https://doi.org/10.2224/sbp.2014.42.1.79

Huang, X. (2012). The Romance of Motivational Leadership: How Do Chinese Leaders 
Motivate Employees? In X. Huang, \& M. H. Bond (Eds.), Handbook of Chinese Organizational Behavior: Integrating Theory, Research and Practice (pp. 184-208). Cheltenham: Edward Elgar Publishing.

Janssen, O. (2001). Fairness Perceptions as a Moderator in the Curvilinear Relationships between Job Demands, and Job Performance and Job Satisfaction. Academy of Management Journal, 44, 1039-1050.

Jaussi, K. S., \& Dionne, S. D. (2003). Leading for Creativity: The Role of Unconventional Leader Behavior. The Leadership Quarterly, 14, 475-498. https://doi.org/10.1016/S1048-9843(03)00048-1

Jung, D. D., Wu, A., \& Chow, C. W. (2008). Towards Understanding the Direct and Indirect Effects of CEOs' Transformational Leadership on Firm Innovation. The Leadership Quarterly, 19, 582-594. https://doi.org/10.1016/j.leaqua.2008.07.007

Kacmar, K. M., \& Ferris, G. R. (1991). Perceptions of Organizational Politics Scale (POPS): Development and Construct Validation. Educational \& Psychological Measurement, 51, 193-205. https://doi.org/10.1177/0013164491511019

Kark, R., Shamir, B., \& Chen, G. (2003). The Two Faces of Transformational Leadership: Empowerment and Dependency. Journal of Applied Psychology, 88, 246-255. https://doi.org/10.1037/0021-9010.88.2.246

Kerr, R., Garvin, J., Heaton, N. et al. (2006). Emotional Intelligence and Leadership Effectiveness. Leadership \& Organization Development Journal, 27, 265-279. https://doi.org/10.1108/01437730610666028

Lee, S., \& Dai, H. (2019). "China Style" and "New Chinese" in Costume Design. Industrial Design, 120-121.

Lee, Y., Zhang, W. H., \& Long, L. R. (2015). The Influence Mechanism of Self-Sacrificing Leadership on Subordinate's Work Performance. Psychological Abstract, 47, 653-662.

Ling, Y., Simsek, Z., Lubatkin, M. H. et al. (2008). The Impact of Transformational CEOs on the Performance of Small- to Medium-Sized Firms: Does Organizational Context Matter? Journal of Applied Psychology, 93, 923-934. https://doi.org/10.1037/0021-9010.93.4.923

Link, A. N., \& Bozeman, B. (1991). Innovative Behavior in Small-Sized Firms. Small Business Economics, 3, 179-184. https://doi.org/10.1007/BF00400023

Liu, D., Zhang, Z., \& Wang, M. (2012). Moderated Mediation and Mediated Moderation: Theory Construction and Model Testing. An Empirical Approach to Organization and Management Research ( $2^{\text {nd }}$ ed., pp 559-590), In X. P. Chen, S. Y. Xu, J. L. Fan, Eds., Beijing: Peking University Press.

Liu, Z., \& Chen, C. H. (2011). The Connotation and Research Prospect of Person-Organization Fit. Chinese Journal of Management, 8, 173-178.

Luoh, H. F., Tsaur, S. H., \& Tang, Y. Y. (2014). Empowering Employees: Job Standardization and Innovative Behavior. International Journal of Contemporary Hospitality Management, 26, 1100-1117. https://doi.org/10.1108/IJCHM-03-2013-0153

Muthén, L. K., \& Muthén, B. O. (2012). Mplus User's Guide (7th ed.). Los Angeles, CA: Muthén \& Muthén,

Ng, T. W., \& Lucianetti, L. (2016). Within-Individual Increases in Innovative Behavior and Creative, Persuasion, and Change Self-Efficacy over Time: A Social-Cognitive Theory Perspective. Journal of Applied Psychology, 101, 14-34.

https://doi.org/10.1037/apl0000029

Peterson, S. J., Walumbwa, F. O., Byron, K. et al. (2009). CEO Positive Psychological Traits, Transformational Leadership, and Firm Performance in High-Technology Start- 
Up and Established Firms. Journal of Management, 35, 348-368.

https://doi.org/10.1177/0149206307312512

Pieterse, A. N., Van Knippenberg, D., Schippers, M. et al. (2010). Transformational and Transactional Leadership and Innovative Behavior: The Moderating Role of Psychological Empowerment. Journal of Organizational Behavior, 31, 609-623. https://doi.org/10.1002/job.650

Rajagopalan, N., \& Datta, D. K. (1996). CEO Characteristics: Does Industry Matter? Academy of Management Journal, 39, 197-215. https://doi.org/10.5465/256636

Saeed, B. B., Afsar, B., Cheema, S. et al. (2018). Leader-Member Exchange and Innovative Work Behavior: The Role of Creative Process Engagement, Core Self-Evaluation, and Domain Knowledge. European Journal of Innovation Management, 22, 105-124. https://doi.org/10.1108/EJIM-11-2017-0158

Sattayaraksa, T., \& Boon-Itt, S. (2016). CEO Transformational Leadership and the New Product Development Process: The Mediating Roles of Organizational Learning and Innovation Culture. Leadership \& Organization Development Journal, 37, 730-749. https://doi.org/10.1108/LODJ-10-2014-0197

Sluss, D. M., \& Ashforth, B. E. (2007). Relational Identity and Identification: Defining Ourselves through Work Relationships. Academy of Management Review, 32, 9-32. https://doi.org/10.5465/amr.2007.23463672

Sluss, D. M., Ployhart, R. E., Cobb, M. G. et al. (2012). Generalizing Newcomers' Relational and Organizational Identifications: Processes and Prototypicality. Academy of Management Journal, 55, 949-975. https://doi.org/10.5465/amj.2010.0420

Tajfel, H., \& Turner, J. (2001). An Integrative Theory of Intergroup Conflict (pp. 94-109). New York, NY: Psychology Press.

Tajfel, H., \& Turner, J. C. (1985). The Social Identity Theory of Intergroup Behavior. In S. Worchel, \& W. G. Austin (Eds.), Psychology of Intergroup Relations (pp. 7-24). Chicago, IL: Nelson-Hall.

Tan, X. H. (2012). The Impact of Matching Person-Organizational Values on Employees' Work Commitment and Organizational Support. Psychological Science, 35, 973-977.

Tang, Y. H., Lu, X. F., \& Lee, K. (2010). The Concept, Measurement Strategy and Application of Person-Organization Matching. Advances in Psychological Science, 18, 1762-1770.

Tsui, A. S., Zhang, Z., Wang, H. et al. (2006). Unpacking the Relationship between CEO Leadership Behavior and Organizational Culture. Leadership Quarterly, 17, 113-137. https://doi.org/10.1016/j.leaqua.2005.12.001

Van Knippenberg, D., Van Knippenberg, B., De Cremer, D. et al. (2004). Leadership, Self, and Identity: A Review and Research Agenda. The Leadership Quarterly, 15, 825-856. https://doi.org/10.1016/j.leaqua.2004.09.002

Van Vianen, A., Dalhoeven, B., \& De Pater, I. E. (2011). Aging and Training and Development Willingness: Employee and Supervisor Mindsets. Journal of Organizational Behavior, 32, 226-247. https://doi.org/10.1002/job.685

Verquer, M. L., Beehr, T. A., \& Wagner S H. (2003). A Meta-Analysis of Relations between Person-Organization Fit and Work Attitudes. Journal of Vocational Behavior, 63, 473-489. https://doi.org/10.1016/S0001-8791(02)00036-2

Wexley, K. N., Alexander, R. A., Greenawalt, J. P. et al. (1980). Attitudinal Congruence and Similarity as Related to Interpersonal Evaluations in Manager-Subordinate Dyads. Academy of Management Journal, 23, 320-330. https://doi.org/10.5465/255434

$\mathrm{Xu}$, C. J., \& Shi, K. (2005). Contingency Analysis of Transformational Leadership and 
Transactional Leadership. Advances in Psychological Science, 13, 672-678.

Yan, Z., \& Chen, C. C. (2013). Developmental Leadership and Organizational Citizenship Behavior: Mediating Effects of Self-Determination, Supervisor Identification, and Organizational Identification. The Leadership Quarterly, 24, 534-543. https://doi.org/10.1016/j.leaqua.2013.03.007

Young, L. D. (2012). How to Promote Innovative Behavior at Work? The Role of Justice and Support within Organizations. Journal of Creative Behavior, 46, 220-243. https://doi.org/10.1002/jocb.15

Yu, G. L., Liang, X. J., \& Fu, B. (2019). Personal-Environment Matching Theory. 60 Theories Commonly Used in Management and Organizational Research (pp 276-283). In C. P. Lee, S. Y. Xu, Eds., Beijing: Peking University Press.

Zhao, H. J. (2013). The Mechanism of Personal-Organization Matching on the New Generation of Employee Engagement. Economic Management, 35, 65-77.

Zhao, H. J., \& Long, L. R. (2004). The Research Status and Prospect of Person-Organization Matching. Advances in Psychological Science, 12, 111-118.

Zhao, H. J., \& Long, L. R. (2008). The Impact of Person-Organizational Fit on Employee Turnover Intention. Nankai Business Review, 11, 56-63.

Zhao, H. J., \& Long, L. R. (2009). Person-Organization Fit and Job Satisfaction. Industrial Engineering and Management, 14, 113-117.

Zhao, H. J., \& Long, L. R. (2010). The Influence of Value Matching and Ability Matching on Employee Turnover Intention in Central Region. Science of Science and Management of S.\&.T., 31, 170-177. 